\title{
CIRCULATION CONTROL: OFF-LINE, ON-LINE, OR HYBRID
}

Michael K. BUCKLAND, Bernard GALLIVAN: Library Research Unit University of Lancaster, England

The requirements of a computer-aided circulation system are described. The characteristics of off-line systems are reviewed in the light of these requirements. On-line systems are then reviewed and their economic viability queried. A "hybrid" system (involving a dedicated mini-computer in the library, used in conjunction with a larger machine), appears to be more cost-effective than conventional on-line working.

\section{INTRODUCTION}

An important feature of a very small library is the close contact between the librarian, his collections, and his users. Over the years as collections and library usage have both increased enormously, librarians have gradually been losing this important "contact." The trend toward increased book use is a desirable one but the sheer pressure of transactions has necessitated the adoption of manual and photographic circulation control systems which concentrate on a restricted range of information about borrowing -notably when a book is due back and who has a given book. Computerbased circulation systems offer the prospect of regaining detailed knowledge of book usage-at a price. This paper reviews three approaches.

The desirable features of a circulation control system are that:

1. It should "marry" borrower, book, and date information together rapidly and accurately.

2. It should enable rapid, easy consultation of the issue files at any time in order to detect the location of any book.

3. It should be able to immediately detect and register the fact that an item just returned from loan has been requested by another reader. This ability should not be dependent on whether or not the person returning the book has also remembered to bring in a recall notice. 
4. It should prepare suitable overdue notices for books retained too long.

5. It should be possible to produce lists of items out on loan to any given borrower and also to signal "overborrowing" (i.e., having an excessive number of books out on loan at any given time).

6. It should be able to detect delinquent borrowers at the point of issue.

7. When material is returned from loan, the system should amend the circulation records promptly and permit the calculation of any fine.

8. It should facilitate the collection, analysis, and presentation of the "management information" needed to maintain effective stock control and high standards of service.

9. It should perform these tasks reliably and economically.

These requirements vary in importance from library to library, but, with some differences in emphasis they appear to apply equally to both public and university libraries.

\section{OFF-LINE}

The commonest approach to computer-aided circulation control is to operate in the off-line mode. Well-documented examples are IBM 357's (Southern Illinois), (2) Southampton University library, (phase II), using Friden Equipment, (3) and the current Automated Library Systems (ALS) Ltd. equipment. (4) These systems can perform the basic operations of issuing and discharging books in an economical manner but because they are operating in an off-line manner they experience difficulties in main-

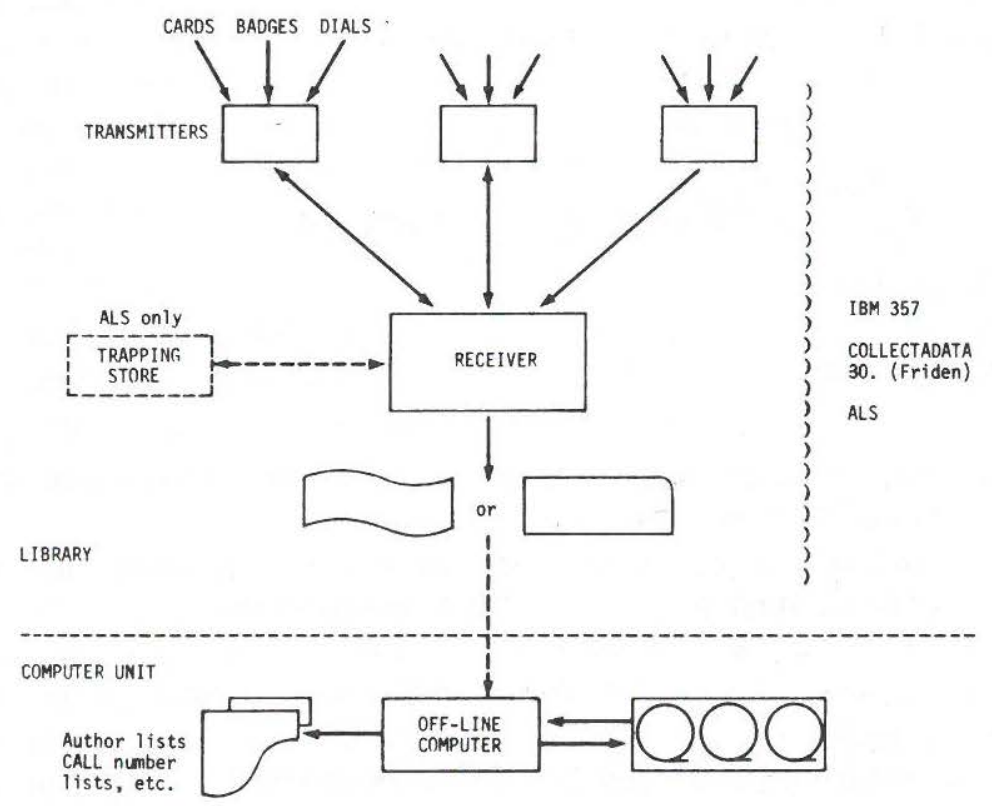

Fig. 1 
taining an up-to-date overview of their collections and in detecting reservations. They cannot detect delinquent readers at the point of issue.

In order to solve some of these problems ALS has been developing an off-line system with a certain amount of storage attached to it. This "trapping store," indicated by dashed lines in Figure 1 (see p.31), can contain the numbers of reserved books and delinquent readers to facilitate immediate identification at the point of issue. This system has proved to be quite popular and at least fifteen have been installed in university and public libraries. It is still not able to provide any better currency of information than is possible with a basic off-line system and the ALS system will handle only numeric information. Books are identified by number only, so that if one receives an overdue reminder, it is because books 341672,816649 , and 654321 are overdue-unless there is a substantial matching operation against a complete catalog file. In contrast a system using alpha-numeric characters could include brief author, title, and call-number information on, say, an 80-column book card. This would permit the production of lists by author, etc., without reference to a complete catalog file.

It may be noted by reference to Table 1 that an outstanding virtue of the ALS system is the low cost of installing additional data collection points. A notable desideratum in library automation is the apparent lack of a simple, inexpensive data collection unit capable of reading alpha-numeric book cards. If relatively expensive equipment is used (e.g., IBM 357 or Friden Collectadata), there may be difficulties in coping economically with the inherent peakiness of library borrowing. Attempts to mould

Table 1. Off-Line Circulation System Costs

\section{IBM 357 Friden Collecta data 30}

Basic Two Transmitter and

Receiver System _..-\$13,000

Maintenance

(p.a.)

655

$$
\$ 14,000
$$

900

$\overline{\$ 14,900}$
ALS (6-reader system)

$\$ 10,000$

800

$\frac{11,000}{\$ 21,800}$

Notes: 1 . The specifications are intended to represent two service points. Since ALS equipment uses separate card readers for borrowing and return, the provision for two borrowing points and two return points would, in fact, have a higher traffic capability than the other two systems.

2. Figures representing British prices expressed as U.S. dollars at $\$ 2.40=£ 1$.

3. Collecta Data 30 hardware is at 1967 price.

4. Approximate cost of each ALS reader is $\$ 500$. 
library use to suit the machinery are unlikely to prove satisfactory. Notably a general lengthening of loan periods will result in a lower standard of library service in terms of immediate availability (1) and, almost certainly, a decrease in actual book usage. In management information terms, the symptoms of this would be an increase in the size of the issue file compared with the borrowing rate and a drop in issues per capita.

\section{ON-LINE}

Since the deficiencies of off-line working are serious, various attempts have been made to develop on-line circulation systems (see Figure 2). This is the second main formula of which Illinois State library (5), Queens University, Belfast (6), and Midwestern University library (7) provide welldocumented examples. Such a system is able to maintain a completely up-todate picture of the issue files. They can detect both reserved material and delinquent readers immediately and appear to provide the complete answer to the library's needs until their technical requirements are examined. In order to control the circulation system in an on-line manner, the library expects there to be at least ten hours on-line working available to it each working day. As more than one university library has already discovered, this number of hours of on-line working is very rarely available at present when computer facilities are being shared with many other users as in a university environment. Furthermore, it is unlikely

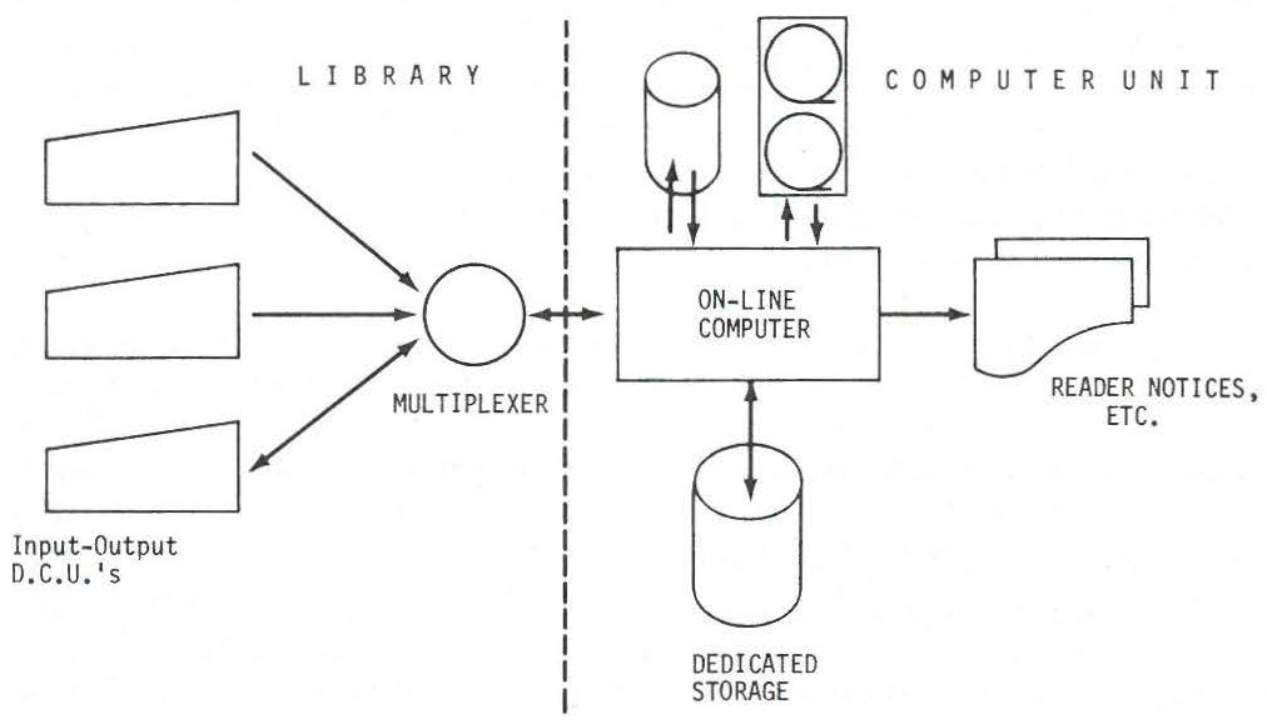

Fig. 2. On-Line Circulation Control 
to become available for quite some years in the future because, with present machines and techniques, on-line working is an inefficient mode of operation unless the computer system is running well below capacity. A further obstacle when sharing facilities is the amount of dedicated storage that must be made available to the library. Storage is a much prized commodity and computer centers are unwilling to forfeit valuable storage for any length of time.

It should also be noted that no average-sized library will be able to afford or justify possession of its own dedicated computer adequate for on-line working. A library's requirements for storage, printing facilities, and so on would make such an independent system an extravagance since its power would have to be considerable to handle the vast quantities of data input to it, but it would constitute a grossly under-utilized investment compared with the sharing of the facilities provided in a university or local government computing center.

The data collection units could be teleprinters or card reading stations with some printing or display facilities. The number and type of such DCU's will depend on the local work load, but we will consider a system using two alpha-numeric card reading stations with printout facilities plus an interrogating printer. An interface into the main computer and a multiplexing device will also be required.

In order to answer queries and to control the circulation in a completely on-line manner the dedicated disk must be large enough to hold the issue file, and having gone to the expense of controlling the issue online, it would seem inconsistent to be satisfied with a number-only system. If we plan for an expected maximum number of 50,000 records in our issue file at any one time and allow 100 characters per record (i.e., author/ title, class or call number, borrower number, date due back, code to describe the type of loan, i.e., long or short, etc.), the disk must be capable of storing 5 million characters. Since it is usual to store the bulk of the circulation control programs on the same disk and to allow certain parts of the disk to be used as work areas, a total store area of 6 million characters, at least, will be required.

The cost of providing adequate dedicated disk storage will depend on the local situation but could well cost anything between $\$ 30,000$ and $\$ 50,000$ to purchase. The remaining equipment is likely to cost $\$ 20,000$ and development costs will be greater than with off-line.

\section{A "HYBRID" CIRCULATION CONTROL SYSTEM}

It is possible to meet all the requirements of a library circulation system in a cost-effective manner by exploiting and combining the main advantages of on-line and off-line working in a hybrid system. The basic structure of such a system is shown in Figure 3 (see p. 36). As can be seen, the mini-computer is sited in the library building and has the various data collection terminals attached locally to it. The mini-computer is also con- 
nected via a line to the main computer into and from which it can send and receive data. The important differences between this system and the conventional on- or off-line systems are that:

1. The mini-computer spools up the transactions as they occur, into its own storage (either tape or disk).

2. The on-line link to the main computer is only used two or three times each day. This is important, since it implies that the Hybrid system does not require continuous on-line facilities.

3. Supplementary or full listings show the state of the issue file at a particular time.

4. The recent transactions stored by the mini-computer can be interrogated and, in conjunction with the listings, gives the immediately current state of the issue file.

5. Reserved books and delinquent readers have their identifiers stored in the core of the mini-computer to enable their immediate identification at the point of issue.

6. The necessity for dedicated equipment on the main computer (such as a dedicated disk) is avoided.

A fairly heavily used library will be handling approximately 5,000 transactions each day. Since these transactions will be either issue or return transactions, in the main, if we allow 100 characters worth of information to identify an issue and 20 characters to identify a return, then on the average we will be handling 300,000 characters worth of information each day.

In the Hybrid system the mini-computer is acting as a controller to the data collection devices and is spooling this information up onto a magnetic tape until such time as the storage space is becoming full or until a sufficient time has elapsed since the last updating of the records. At this time the mini-computer passes the information on its magnetic tape to the main computer via the on-line link. The duration of the on-line connection might be ten to fifteen minutes owing to line speed limitations. In order to operate a hybrid system, the library would need two periods of on-line working each day of approximately ten to fifteen minutes each.

Alternatively the magnetic tape could be physically replaced, the fresh one continuing to record transactions while the full one is carried manually to the main computer. Provided that the tapes can be read by the main computer, on-line facilities would not be required.

The recent transactions, having been passed to the main computer, will be sorted and merged with the rest of the issue file which would be kept on magnetic tape. The precise nature of the listings produced by the main computer will depend on local factors, such as the duration of the loan period, etc., but could be either a fully revised complete listing or a listing of the most recent transactions to supplement an earlier complete listing. 


\section{HYBRID Computer Costs}

Basic Computer (includes Teleprinter)

Extra $4 \mathrm{k}$ of store

Tape controller

Dual tape transport

Data break interface

It is worth noting that the most widely adopted computer-aided circulation system in Great Britain is the ALS system, which, if purchased with a "trapping store," is the nearest equivalent to the hybrid system outlined in Figure 3. The chief differences are that (1) the ALS system operates on numbers only, which, in our view makes it less suitable for university library applications; (2) the "trapping store" is inflexible in its capability when compared with a mini-computer of similar cost.

In order to utilize the on-line facilities provided by a mini-computer to the full, it would be possible to handle the "short loan" reserve collections of popular texts (commonly borrowable for a few hours only) in a completely on-line manner. In this respect there would be no reliance on the main machine. It might also be appropriate to use the mini-computer to handle other library data processing tasks.

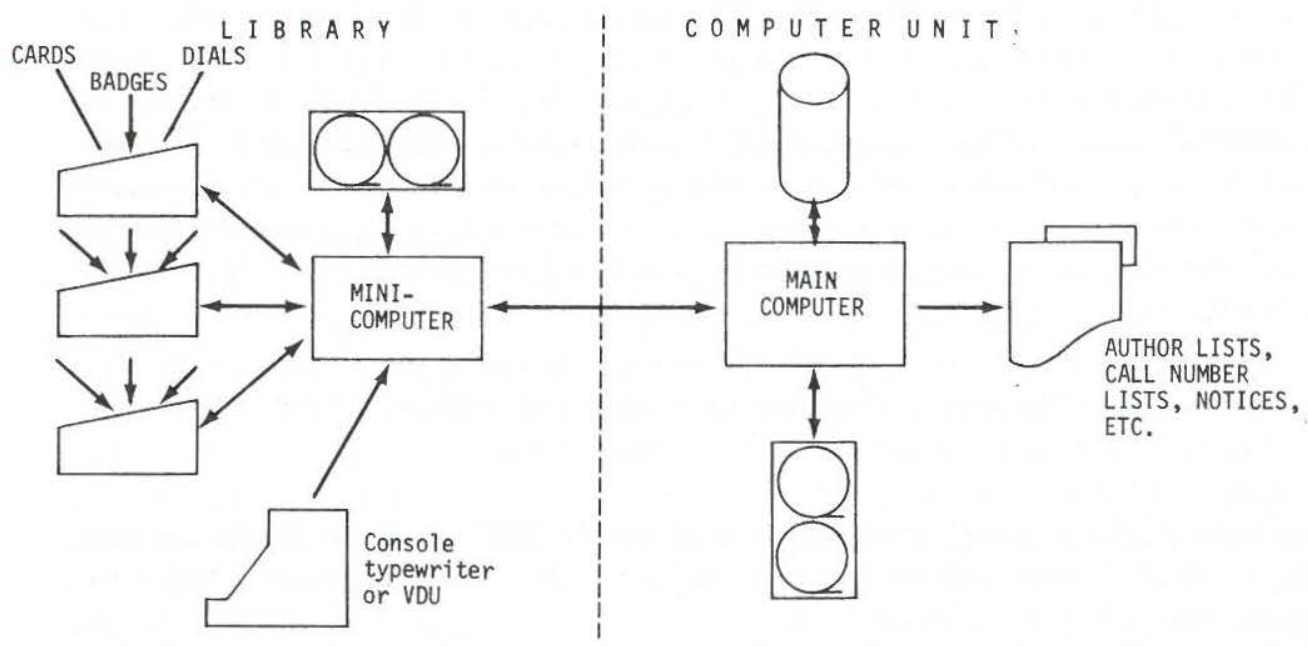

Fig. 3. Simplified Hypothetical "Hybrid" Circulation Control System 
Last year at the University of Lancaster the average cost per issue was 12.72 cents. Since the University of Lancaster is a new university in Great Britain, it is in the middle of a period of growth and student numbers are expected to increase from 3,000 to 5,400 in the next five years. This university has also researched into the influence of duplication and loan period adjustment on the availability of stock to prospective users and with the present level of duplication and grades of loan period there is a per capita borrowing rate approaching 80 issues per annum. This figure is expected to increase in the next five years. With these figures as a basis, at least 2 million issues are expected in the next five years. Even allowing for the cost of data conversion and the amortizement of hardware over five years, the use of a hybrid circulation control system could be expected to result in an average cost per issue of just under 12 cents.

\section{CONCLUSION}

The costs already mentioned can be tabulated thus:

$$
\begin{aligned}
& \text { off-line- } \$ 13,000-\$ 22,000 \\
& \text { on-line- } \$ 70,000 \\
& \text { Hybrid- } \$ 35,000
\end{aligned}
$$

This suggests that a Hybrid system offers complete control over library circulation in a highly cost-effective manner compared with on-line working. Whether or not a hybrid system is also to be preferred to off-line working will depend on the individual library context. The trade-off between the marginal advantages and the marginal increases in cost and complexity will depend on the detailed costs and value-judgments specific to each situation.

If our diagnosis is correct then most attempts to progress from off-line to on-line working are ill-judged and would appear to have no justification in cost-effectiveness. In our view these developments are unlikely to become fully operational. If they do, their life will probably be short or restricted to limited hours unless exceptional circumstances prevail. Such circumstances would include continuing subsidies for research and development or the existence of a system justified on other grounds (e.g., police records).

\section{REFERENCES}

1. Michael K. Buckland and others, Systems Analysis of a University Library; Final Report on a Research Project, University of Lancaster Library Occasional Papers, 4 (Lancaster, England: University of Lancaster Library, 1970).

2. R. E. McCoy "Computerised Circulation Work: A Case Study of the 357 Data Collection System, Library Resources \& Technical Services 9:59-65 (Winter 1965).

3. B. A. J. McDowell and C. M. Phillips Circulation Control System. Automation Project Report No. 1 (SOUL/APR1) (Southampton, England: University of Southampton Library, 1970). 
4. Lorna M. Cowburn "University of Surrey Automated Issue System," Program 2:70-88 (May 1971).

5. Robert E. Hamilton "The Illinois State Library "On-Line" Circulation Control System," in Dewey E. Carroll ed., Proceedings of the 1968 Clinic on Library Applications of Data Processing. University of Illinois Graduate School of Library Science, Urbana, Illinois (London: Bingley, 1969), p.11-28.

6. Richard T. Kimber, "An Operational Computerised Circulation System with On-Line Interrogative Capability," Program 2:75-80 (Oct. 1968).

7. Calvin J. Boyer and J. Frost, "On-Line Circulation Control-Midwestern University Library's System Using an IBM 1401 Computer in a "TimeSharing' Mode," in Dewey E. Carroll ed., Proceedings of the 1969 Clinic on Library Applications of Data Processing. University of Illinois Graduate School of Library Science, Urbana, Illinois (London: Bingley, 1970), p.135-45. 